\title{
EDITORIAL
}

\section{AJIS FOUNDING EDITOR, ROB MACGREGOR}

The Australasian Journal of Information Systems (AJIS) began in 1993 and was based on the simple realisation that there was a need for an academic 'outlet' for IS research in Australia. We were fortunate enough in having a large consulting editor base from the recently run $3^{\text {rd }}$ ACIS conference in Wollongong, some of whom have remained with the journal ever since. The development of the journal was not without controversy - some sections of the IS academic community questioning 'whether to support the project or white-ant it.' Our reaction to this was simple - a formal request to become a member of the consulting editor board was sent out and the problem magically disappeared.

AJIS's first success was in 1994, being recognised as a 'strong', non-US journal and we were invited to present the journal's goals and missions at the Vancouver ICIS conference. In the early 2000's AJIS was 'adopted' by the newly formed AAIS and in 2004 reached the position of no. 25 in the world ranking of IS journals.

As editor from 1993 - 2005 I was fortunate to work with many gifted and insightful authors and a large, hard-working and dedicated group of consulting editors. This facet of the editorship I will miss. Apparently my colleagues have also indicated that they miss my storming up and down corridors questioning the parentage of Microsoft Word as it invokes some hitherto unknown rule at publishing time.

I would like to extend my thanks to everyone who worked with the journal - the authors, the consulting editors and particularly the staff of the Department of IS, University of Wollongong, without whom the journal would not have been printed or distributed.

AJIS belongs to the Australasian IS community. With your ongoing support, its future is assured. I would like to wish the new editors every success and I hope they will gain as much from the role as I have.

Rob MacGregor

Associate Professor of Information Systems

University of Wollongong

May 2006 